\title{
ph

\section{La dehesa de los Pedroches: patrimonio natural y cultural}

Centro de Interpretación de la Dehesa

URL de la contribución <www.iaph.es/revistaph/index.php/revistaph/article/view/3545>

\section{RESUMEN}

La comarca de los Pedroches, con 17 pueblos en $360 \mathrm{~km}^{2}$, es sin duda uno de los espacios naturales más interesantes de toda Andalucía. Forma la dehesa más densa de toda Europa, dehesa que, a través de los siglos, ha conformado una cultura y una forma de relación entre el hombre y el medio ambiente muy característica y, sin ninguna duda, sostenible.

Como lugar de interpretación de este medio surge en 2010, en Villanueva de Córdoba, el Centro de Interpretación de la Dehesa, en una casa del siglo XIX, rehabilitada, y que mantiene las características arquitectónicas propias de los Pedroches, techos altos terminados en bóveda de arista, pasillos anchos, varios cuerpos de casa, y como material constructivo el granito, que se encuentra en espectaculares afloraciones por toda la dehesa.

Otro elemento patrimonial que define la dehesa de los Pedroches son sus paredes de piedra, construidas tradicionalmente sin argamasa y con bloques de tamaños distintos que reciben nombres diferentes: catana, codal, barda, ripio. La función de estas paredes es doble, por una parte definir la propiedad y por otra evitar que los animales circulen libremente de un lugar a otro de la dehesa.

El Centro de Interpretación de la Dehesa explica diversos aspectos de la dehesa, sus características naturales, los usos y oficios que ha propiciado a lo largo de la historia, la cultura peculiar muy influenciada por la proximidad extremeña y castellana y la economía basada fundamentalmente en una ganadería extensiva que se centra en tres especies fundamentales: el cerdo ibérico, la oveja y la vaca.

\section{Palabras clave}

Andalucía | Centro de Interpretación de la Dehesa | Córdoba (Provincia) | Dehesas | Patrimonio cultural | Patrimonio natural | Valle de los Pedroches (Córdoba) | Villanueva de Córdoba | 


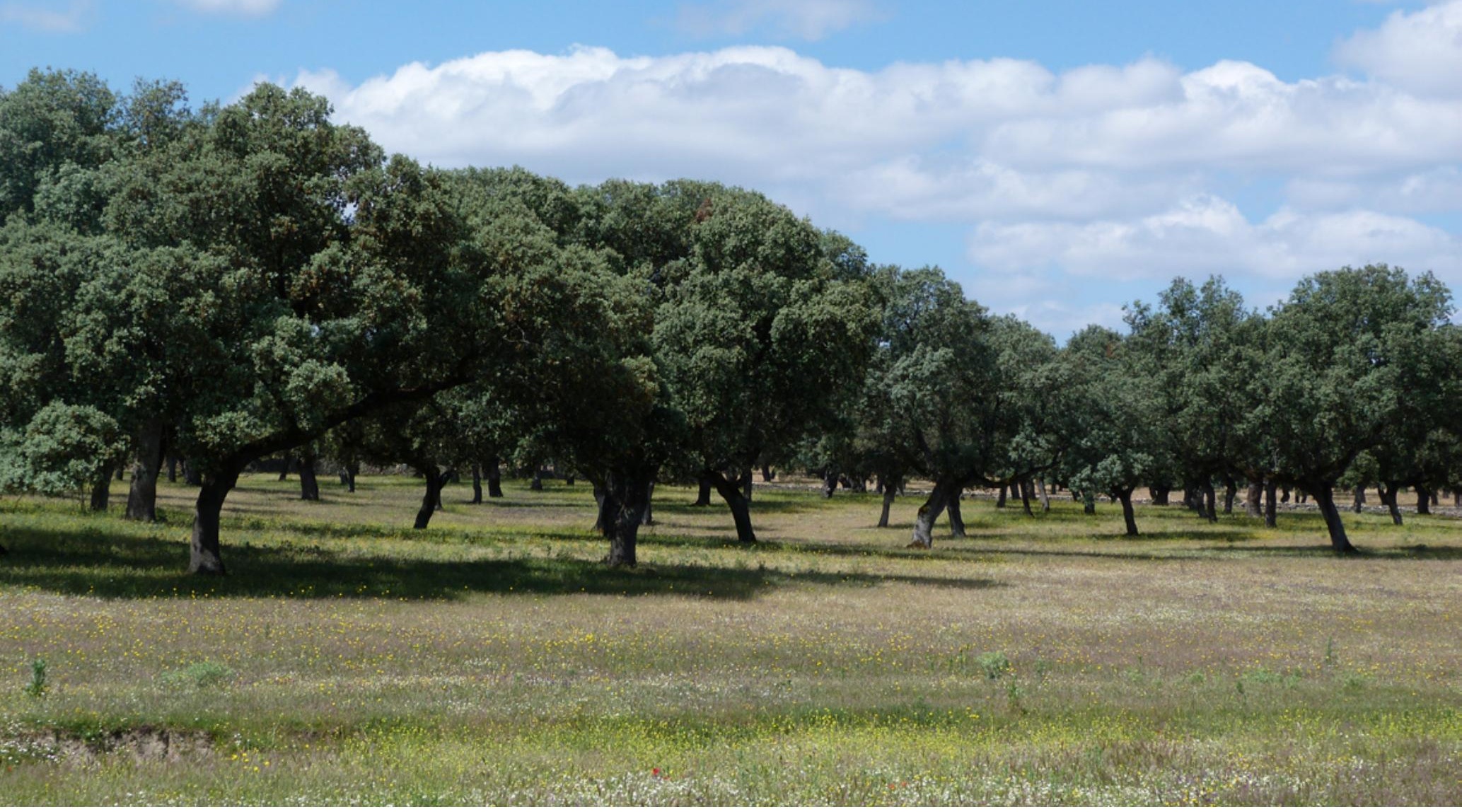

Dehesa | foto Oficina de Turismo del Ayuntamiento de Villanueva de Córdoba (para todas las imágenes del artículo) 
Medio natural antropizado. Bosque medi-terráneo modificado por el hombre para asegurarse su subsistencia.

Centro de Interpretación de la Dehesa, recreación bodega y patio del centro

No cabe duda que si hay un elemento que define a toda la comarca de los Pedroches, éste es la dehesa ${ }^{1}$. Espacio natural creado por el hombre, uno de los mayores exponentes de sostenibilidad y equilibrio entre lo natural y lo humano.

Para conocer este ecosistema desde 2010 se puede visitar, en Villanueva de Córdoba, ubicada en el corazón de la dehesa más poblada de Europa, en los Pedroches, el Centro de Interpretación de la Dehesa. Aquí podemos acercarnos a aspectos tan diversos como el entorno natural, la cultura, la economía, la sociedad, que han creado un espacio propio y característico.

Ubicado en una casa del siglo XIX rehabilitada, que responde a las características arquitectónicas de la comarca pedrocheña: varios cuerpos, en uno de los cuales se situaba la cocina, que calentaba toda la vivienda; techos altos en la planta baja definidos por bóvedas de arista que respondían a una doble funcionalidad, estética y arquitectónica ya que este tipo de arista permite soportar mejor el peso del piso superior, lugar destinado a almacén de grano y matanza; pasillo muy ancho que permitía la entrada de los animales de carga que se llevaban hasta la cuadra situada en la parte posterior de la casa, donde también solía estar el pajar, el huerto y una cocinilla.

Como material se utiliza tanto el granito como la pizarra, trabadas con una mezcla de barro o cal y arena, para todos los muros perimetrales. Las estancias internas se delimitan con ladrillos de barro cocido. Las puertas, ventanas y zócalos de la fachada suelen ser de sillares encalando el resto. Las cubiertas son a dos aguas, hechas con vigas de encina, y con otras vigas menores
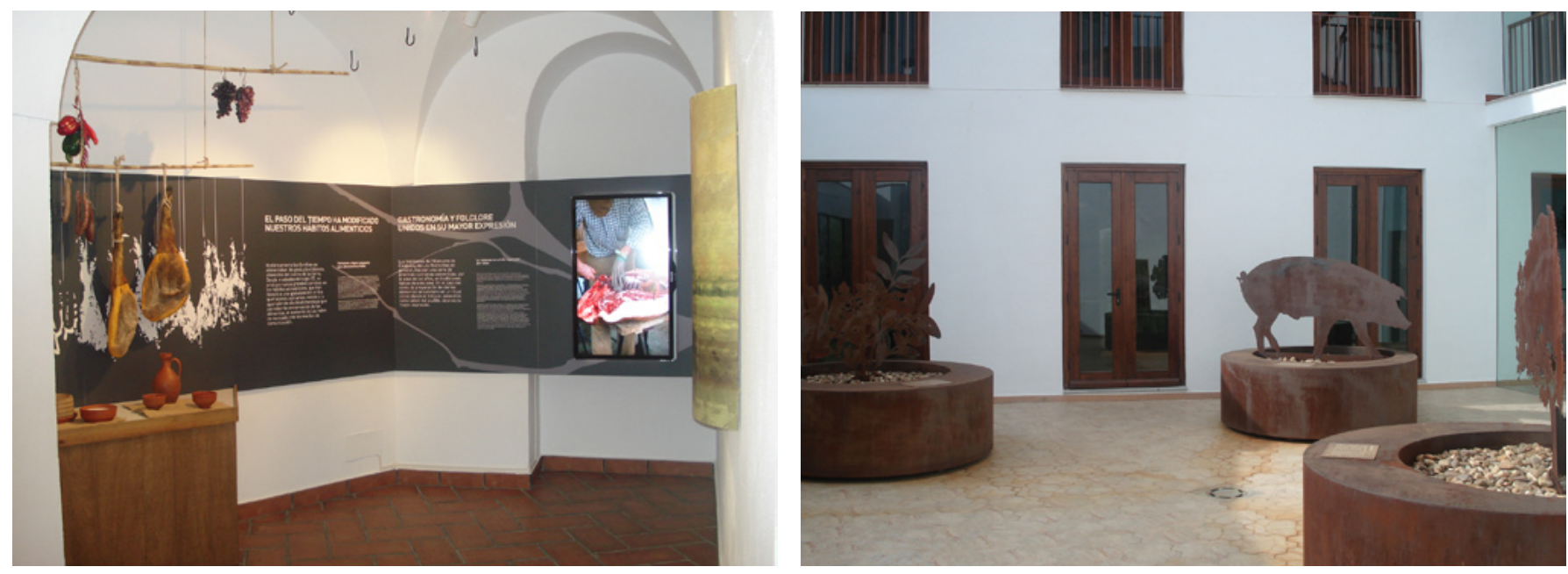
cruzadas transversalmente a las principales, de tablones de madera o "tiguillos" de madroño. Todo se cubre después con teja árabe.

El Centro de Interpretación de la Dehesa ${ }^{2}$ ofrece un recorrido por la historia y los usos de la dehesa a través de paneles explicativos y el uso de las nuevas tecnologías. Los espacios que encontraremos en el centro son los siguientes:

$>$ El lugar: donde se contextualiza la dehesa, dentro de la comarca de los Pedroches, las características humanas, la flora y fauna.

> La raíz: los orígenes. Se hace un repaso por la dehesa desde su origen y la transformación que ha sufrido a lo largo de los siglos por la mano del hombre.

$>$ El tronco: en esta parte expositiva, centrada en el patio, aparece todo lo referente a la flora, tronco de la encina, espinas, flores, bellota, cercado de piedra.

> Las ramas: zona dedicada al visionado de un documental en el que durante 15 minutos se expone la historia, usos, folclore, trabajos, gastronomía, etnología, etc.

> Los frutos: esta última parte se ha destinado a explicar el folclore, la gastronomía, el trabajo, la artesanía que la dehesa ha generado a través de los siglos y que en algunos casos aún perduran.

El proceso histórico de la comarca de los Pedroches ha condicionado de forma definitiva la geografía de las dos subcormarcas pedrocheñas.
2

Más información: http://www.andalucia.org/es/ turismo-cultural/visitas/cordoba/otras-visitas/ centro-de-interpretacion-de-la-dehesa/
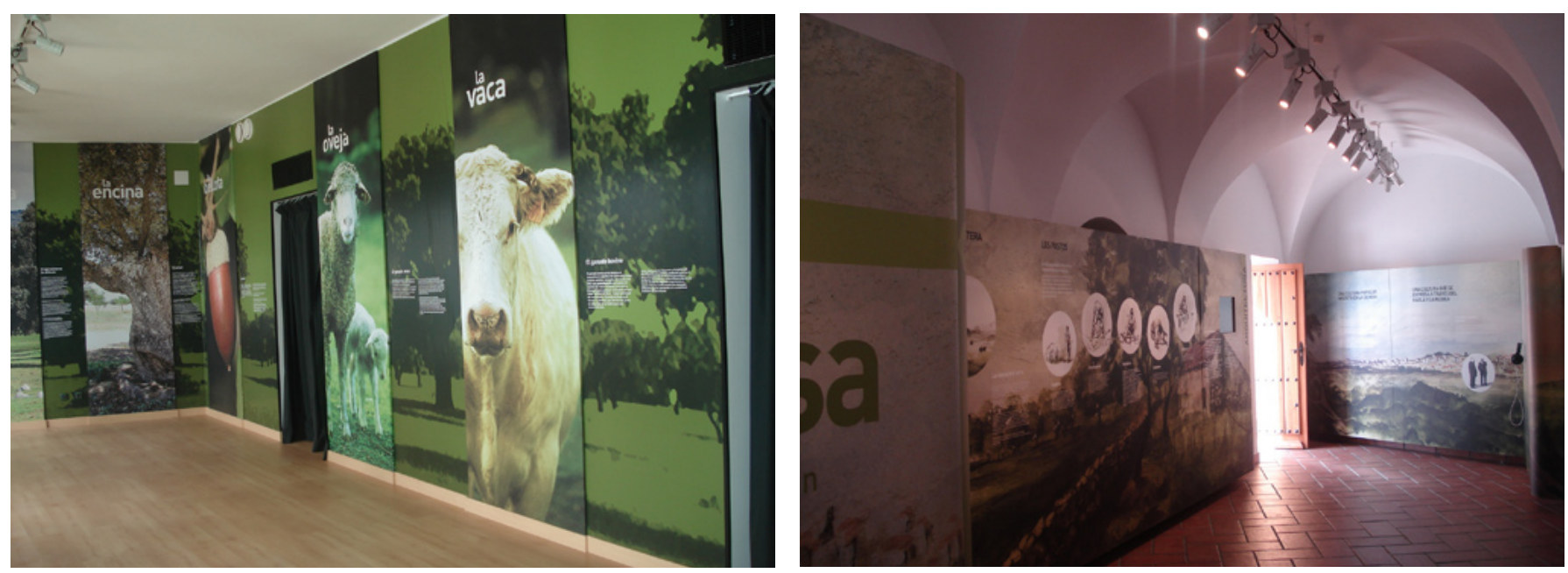
3

Uso del bosque con fines económicos, tala, producción de carbón, picón, etc.

4

Constructores de las paredes de piedra que delimitan las fincas en la dehesa.
Con la creación del señorío de Santa Eufemia en 1293 y el de Belalcázar en 1444 , la zona occidental quedó configurada como zona de señorío, y la subcomarca centro-oriental permaneció como zona de realengo. Esta división jurisdiccional propició notables diferencias paisajísticas.

En la occidental, las parcelas se configuraron como grandes latifundios señoriales, procedentes de la usurpación y el adehesamiento indebido. En la subcomarca centro-oriental predominó la propiedad pública, conviviendo con la privada y, aunque también se produjeron usurpaciones, su incidencia fue mucho menor.

Las desamortizaciones del los siglos XIX y XX, ahondaron en la transformación del bosque mediterráneo, con el traspaso de tierras forestales no cultivables a manos privadas, que inmediatamente se roturaron para obtener mayores beneficios de ellas: venta de carbón, leña, pastoreo, tala y cultivo.

Sin embargo en determinadas zonas, el bosque se vio alterado sólo en los estratos inferiores. Las labores agrícolas y silvícolas ${ }^{3}$ practicadas de una forma inteligente y racional, generaron un bosque equilibrado, conservándose una importante masa de arbolado constituido por encinas, alcornoques y quejigos: la dehesa. A través de esta asociación entre naturaleza e inteligencia, el ser humano ha llevado a cabo un aprovechamiento integrado de suelo y vuelo, es decir, la búsqueda de beneficio en los pastos y las hierbas, necesarias para la alimentación del ganado, y en consecuencia para la obtención de todos los productos derivados, de los arbustos y los árboles, para la extracción de madera y carbón, y de los frutos, como la bellota, para el consumo directo.

El termino "dehesa" proviene del castellano defensa, que denominaría a aquellos terrenos acotados para impedir el pastoreo de ganado trashumante mesteño. La dehesa es por tanto una creación humana a partir de un bosque de encinas primitivas.

El paisaje adehesado de los Pedroches está formado por cercados de piedra realizados por los parederos ${ }^{4}$. Se trata de muros de aproximadamente $30 \mathrm{~cm}$ de anchura y una altura de 1,50 metros. La creación de estas cercas se realizó para preservar los sembrados de los animales, así como para reafirmar la propiedad. Los parederos trabajan en cuadrillas empleando mampuestos que reciben nombres diferentes dependiendo de su tamaño y función: las catanas son piedras de gran tamaño y formas regulares, normalmente empleadas en la base; las codales, son piedras dispuestas transversalmente al eje de la pared, para romper las posibles tensiones; las bardas son las planas que se colocan en lo alto de la pared; los ripios son las pequeñas que rellenan los intersticios. 


\section{BIBLIOGRAFÍA}

- VALLE BUENESTADO, B. (1985) Geografía agraria de Los Pedroches. Córdoba: Excma. Diputación Provincial de Córdoba, 1985

- VALLE BUenestado, B. (1978) Villanueva de Córdoba. Estudio geográfico. Córdoba: Excma. Diputación Provincial de Córdoba, 1978

- ALONSO MORALES, M. (2007) Comarca de Los Pedroches, Córdoba, Andalucía. En LUNA, M.; LUCAS, M. (eds.) Arquitectura tradicional y entorno construido. Murcia: Quaderna, 2007, pp. 331-373 